\title{
Toxoplasmosis in Livestock and Pet Animals in Slovakia
}

\author{
Lenka Luptakova, Eva Petrovova, David Mazensky, \\ Alexandra Valencakova and Pavol Balent
}

Additional information is available at the end of the chapter

http://dx.doi.org/10.5772/47810

\section{Introduction}

The health status of livestock largely reflects on the human population. Livestock is important in terms of production of safe foodstuffs or breeding purposes.

Infections caused by pathogenic protozoa give rise to frequent problems mainly in tropical and subtropical regions, where they are widespread. It is reported that up to 4000 protozoa live as parasites. Worldwide, the most prevalent protozoan infection is malaria, while the most prevalent infection in the Slovak Republic is toxoplasmosis, by which the $30 \%$ of population are infected on average.

Parasitic pathogenic protozoa largely parasitize intracellularly, the course of these infections is acute, often cause the death. On the other hand, they can progress subclinically. The latent respectively chronic stage can follow the acute form and infections can persist throughout the whole life of the host. The course of the disease mostly depends also on the pathological agents. They stimulate the innate and adaptive immune response of the host. In mostly protozoan infections the immune response is not so sufficiently effective for a complete destruction of the parasite. This situation ensures the survival of the parasite and it is the characteristic feature for mostly protozoan infections.

Since a total elimination of the influence of negative factors (including pathogens) in each animal species is impossible, in the case of an unexpected outbreak of disease the solution is in its rapid and reliable diagnostics. The detection of pathogens as infection agents is carried out in laboratories using multiple techniques. The direct proof of parasite is usually microscopically and it is clear confirmation of infection. In systematic infections where the direct proof of parasite is unlikely serological methods are carried out in diagnostics for detection of antigen or antibody present in the biological samples. Serological methods often 
don' $t$ solve the problems of diagnosis in the early stage of infection or in the case of latent infection. For diagnostics of these stages are required more sensitive laboratory methods. In At present molecular methods based on the detection of the nucleic acid are used in the laboratories. A polymerase chain reaction (PCR - standard or quantitative) has wide range of using in the detection of parasites.

Toxoplasmosis is an acute parasitic infection monitored based on the epidemiological situation in the country. Therefore it is necessary to interconnect an epidemiological monitoring of infection in humans and animals because of a zoonotic character of this infection.

We here review the information available on the seroprevalence of $T$. gondii infection in livestock and pet animals in Slovakia. In addition we discuss the various serological and molecular methods available for the diagnosis of toxoplasmosis (in animals) and suggest a diagnostic approach based our data.

\section{Basic characteristics about T. gondii}

Toxoplasma gondii is a protozoan parasite of great medical and veterinary importance. Toxoplasmosis is one of the most common parasitic zoonoses in the world afflicting a broad range of both mammals and birds. The aetiological agent is $T$. gondii whose definite hosts are representatives of the family of Felidae infected by oocysts from the environment, or by tachyzoites and bradyzoites from intermediary hosts, such as all kinds of vertebrates, including humans. It is a pantropical cosmopolite and facultative heterogenic coccidia. $T$. gondii causes a mild infection in immuno-competent hosts, but in the immuno-compromised hosts, foetus and neonates, toxoplasmosis is severe even leading to death [1].

Toxoplasmosis may affect a number of organs, but it primarily affects lungs, the CNS (central nervous system) and eyes. Canine and feline toxoplasmosis is a multi-systemic disease; however a latent form of the disease usually develops. Dogs may act as a mechanical factor in transmitting toxoplasmosis to humans by rolling in foul-smelling substances and by ingesting fecal material. Just remember that $50 \%$ of stray dogs and dogs carry T. gondii antibodies, which means that they have been infected and may transmit the parasite. Cats are very important hosts in the epidemiological cycle of $T$. gondii, a zoonotic protozoan parasite that can infect humans and many other animal species worldwide. People and especially immuno-compromised individuals and pregnant women should observe the hygienic principles not only after contact with soil, cats, before eating, but also after contact with dogs. In gravid animals, particularly in sheep and goats, the T. gondii infection causes embryonic mortality, foetus death or abortion depending on the stage of gravidity in which the infection occurred. Variation in the clinical presentation and severity of disease has been attributed to several factors, including the heterogeneity of the host and the genotype of the infective parasite. The sources of the contamination by oocysts are mainly moist and shady places with the occurrence of cats where are suitable conditions for surviving of oocysts for a long period in the external environment [2]. Sheep were in fact the first mammals in which congenital toxoplasmosis were proven with abortions, dead-born 
fetuses and frequent manifestations of infection including infertility. The first case of manifest toxoplasmosis in sheep with symptoms of encephalomyelitis and tachycardia was described by Olafson and Monlux [3]. Sheep are most frequently infected with T. gondii from environment, i.e. from feed and pasture.

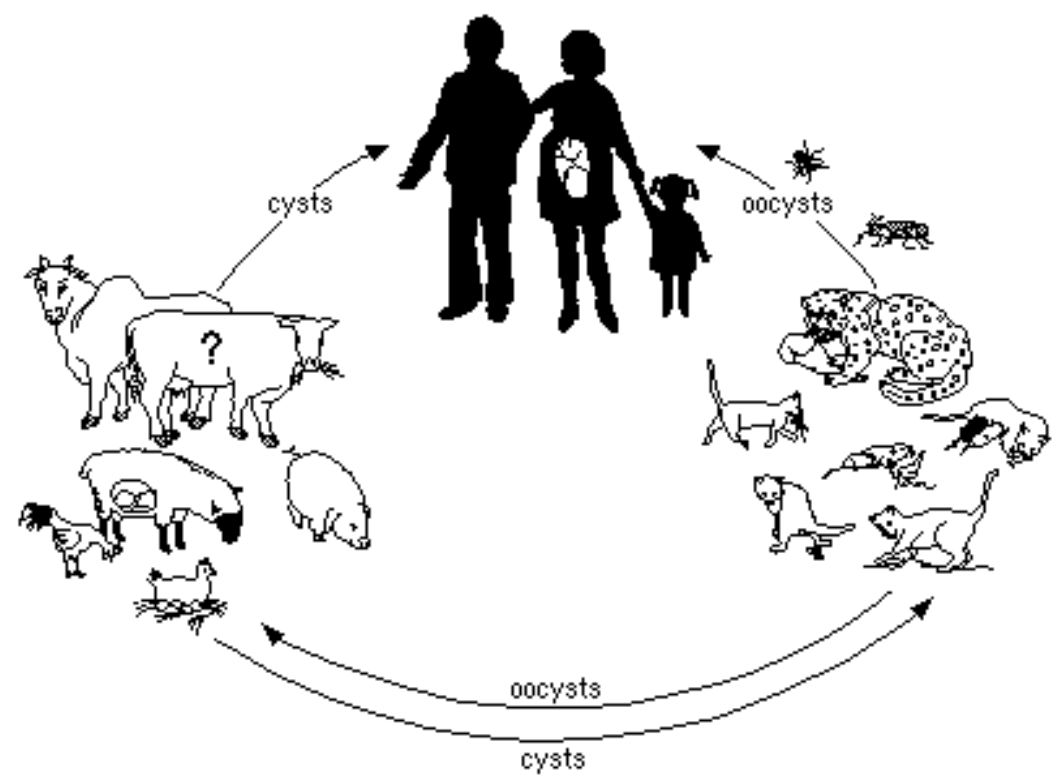

Figure 1. $T$. gondii - life cycle

\section{3. $T$. and the immune system}

T. gondii is able to survive and persist in immuno-competent intermediate hosts for the host's life. This is despite the induction of a vigorous humoral and more importantly cellmediated immune response during infection. T. gondii has evolved multiple strategies to avoid or to interfere with potentially efficient anti-parasitic immune responses of the host immune evasion includes indirect mechanisms by altering the expression and secretion of immunomodulatory cytokines or by altering the viability of immune cells and direct mechanisms by establishing a lifestyle within a suitable intracellular niche and by interference with intracellular signaling cascades, thereby abolishing a number of antimicrobial effector mechanisms of the host [4].

\section{Non-specific immune response}

In immuno-competent hosts this parasite activates asymptomatic chronic infection, what make possible its transmission and survival. The infection of $T$. gondii may be lethal for immuno-compromised patients. At the beginning of immune response parasite changes to 
bradyzoites, which persist in tissue cyst for life. T. gondii is capable of triggering the nonspecific activation of macrophages and natural killer cells (NK-cells) along with other haematopoietic and non-haematopoietic cells. This activation is intended to limit parasite proliferation due to its direct or indirect cytotoxic action and to trigger a specific immune response due to the presentation of $T$. antigens. Non-specific response begins immediately following the first contact between the parasite and the host [5]. NK-cells take part in early phase of immune response. During the early phase of the infection, it is through the combined and synergetic action of the NK-cells and the macrophages, activated by IFN- $\gamma$. In activated macrophages vacuoles of lived tachyzoites merge with lysosomes and then follow out the destruction of parasites. Neutrophils and, very probably, eosinophils, and mast cells rapidly interfere to the infection and are involved in setting up a non-specific early immune response via the production of IL-12 and various proinflammatory factors [6].

\section{Specific immune response}

The non-specific immune response has led to differentiation of macrophages and Blymphocytes into antigen presenting cells. The effector cells are stimulated by dendritic cells presenting the antigen to T-lymphocytes. This mechanism requires a close interaction between the antigen presenting cell and the T-lymphocytes [7]. The interaction of parasite with mechanisms of non-specific immune response is important to orientation of progress of specific immunity. The induction of IL-12 and then IFN- $\gamma$ stimulate the progression of Th1 subpopulations so that polarize the immune response for behoof cellular immunity. After acute infection, the cells presenting antigens (macrophages) are exciting to produce IL-12 and initiate differentiation of immature CD4 T-lymphocytes to Th1. The cellular immunity initiates the production of IFN- $\gamma$. This cytokine effects as a major mediator of cellular immunity during toxoplasmosis. The key function in specific immune response plays Tlymphocytes. These effector cells, which are involved in resistance to $T$. infection, then exert their function via a cytotoxic activity and/or the secretion of cytokines involved in the regulation of immune response [8].

$\mathrm{CD}^{+}$and $\mathrm{CD} 8{ }^{+} \mathrm{T}$-lymphocytes are the main players involved in resistance of the host to $\mathrm{T}$. infection $\mathrm{CD}^{+} \mathrm{T}$-lymphocytes are required for the development of resistance during the early phase of the infection, and for immunity during vaccination. The CD8 $8^{+}$-lymphocytes exert a cytotoxic activity against tachyzoites or cells infected with T. gondii [9].

\section{Humoral immune response}

Antibodies play a minor role but remain the essential means for diagnosing toxoplasmosis. The production of specific IgG antibodies usually begins 4 weeks after the infection and can continue for several months while the dynamics of antibody production does not yield substantial change during the course of disease. IgG are the second immunoglobulins to appear in toxoplasmosis. They play a role in protection of the foetus because they are capable of crossing the placenta. The main target antigens of IgG are the surface antigens of the parasite [6]. 
IgM antibodies may appear earlier and decline more rapidly than IgG antibodies. The serum IgM only appears at the end of the first week following infection. These immunoglobulins are the best activators of the complement system. Due to their structure, they enable excellent agglutination and have a high level of cytotoxicity. This phenomenon is used especially in serological diagnosis techniques. Their persistence is subject to a high level of individual variation and can be as much as a year in most cases, thanks to the use of increasingly sensitive detection techniques [6].

IgA may be detected in sera of actuely infected adults and congenitally infected infants. In acquired toxoplasmosis, the appearance of $\operatorname{IgA}$ is not systematic. In immunodepressed subjects, IgA is thought to be an early marker in $50 \%$ of cases. In congenital toxoplasmosis, the detection of $\operatorname{IgA}$ is valuable, since these can be detected in the absence of IgM. IgA (like $\operatorname{IgM}$ ) do not cross the placenta and are actively involved in the diagnosis of congenital toxoplasmosis $[2,13]$.

IgE antibodies are detectable in sera of actually infected adults, congenitally infected infants and children with congenital toxoplasmic chorioretinitis. The appearance on $\operatorname{IgE}$ in acute or congenital toxoplasmosis is random. The presence of this isotype is correlated with the beginning of complications, such as adenopathies, chorioretinitis, and T. reactivations in immunodepressed subjects [1].

\section{Acute and chronic infection}

Cell-mediated immune responses are essential for host control of intracellular infections. $T$. gondii is a protozoan parasite that infects multiple vertebrate species and invades multiple cell types. Upon initial encounter with the immune system, the parasite rapidly induces production of the protective cytokine IL-12 most likely from a subpopulation of dendritic cells. NK and T-lymphocytes are then activated and triggered to synthesize IFN- $\gamma$, the major mediator of host resistance during the acute and chronic phases of infection. Cytokine (IFN$\gamma$ and TNF-alpha) rather than cytotoxicity-based effector functions are more critical for protective immunity both during the acute and chronic phases of T. gondii infection. [10].

The T-lymphocytes, macrophages, and activity of interleukin IL-12 and IFN- $\gamma$ is necessary for maintaining quiescence of chronic $T$ gondii infection. IFN- $\gamma$ stimulates anti-T. gondii activity, not only of macrophages, but also of nonphagocytic cells. TNF-alpha is another cytokine essential for control of chronic infection with T. gondii [11].

\section{Congenital infection}

Congenital toxoplasmosis poses a public health problem, being capable of causing foetal death and ocular and neurological sequelae in congenitally infected children. Congenital infection occurs only when mothers first encounter $T$. gondii during pregnancy. Resistance to T. gondii is mainly mediated by protective cytokines, such as IFN- $\gamma$ and interleukin 2 (IL-2), whereas regulatory cytokines, such as IL-4 and IL-10, are associated with increased susceptibility to infection. Susceptibility of the pregnant host to toxoplasmosis may be due to a regulatory 
cytokine bias that is maintained during gestation. This cytokine pattern of pregnancy enhances susceptibility to toxoplasmosis, together with the risk of placental infection and congenital transmission. Cell-mediated immune responses involving CD4 and CD8 T cells and NK-cells play a protective role in $T$. gondii primary infection [12].

\section{Diagnosis of toxoplasmosis}

The diagnosis of $T$. gondii infection may be establishes by serologic test, amplification of specific nucleic acid sequences (i. e. polymerase chain reaction), histological demonstration of the parasite antigens (i. e. imunoperoxidase stain) or isolation of the organism. Biological diagnostics of infections caused by $T$. gondii can be provided by: direct methods (microscopic analysis, in vitro isolation on cell cultures, histological methods, detection of DNA of T. gondii) and by indirect serological methods to indicate the presence of specific antibodies in serum. Suitable combination of complementary techniques (detection of antibodies in serum and manifestation of parasite), must lead in majority of cases to precise diagnostics of congenital toxoplasmosis. The use of serologic tests for demonstration of specific antibody to $T$. gondii is the initial and primary method of diagnosis. Serological diagnostics of active infection is not reliable, because reactivation is not always accompanied by changes in the level of antibodies and presence of IgM does not indicate present infection. There are several serological tests available for the detection of $T$. gondii antibodies. In one type of test the observer judges the given colour of tachyzoites under a microscope, such as with the dye test (DT) and IFA test. Another depends on the principle of agglutination of $T$. tachyzoites, red blood cells or latex particles, such as with the direct agglutination test (DAT) and indirect haemagglutination test (IHA) and latex agglutination (LA) test, respectively. With the enzyme-linked immunosorbent assay (ELISA), the degree of colour change defines the quantity of specific antibody in a given solution. The most frequently used method for detection of $T$. gondii infection is complement fixation test for antibody detection of IgG class and ELISA tests for detection of the markers of acute infection in IgM, IgA and IgE classes. IFAT method demands intact tachyzoites and it is more sensitive and more specific compared with IHA, LA, ELISA tests, because during infection the first significant rise of IgM and IgG antibodies was observed against cuticular antigens. Diagnostics of acute infection during gravidity in women is difficult. IgM antibodies can be detected a long time after acute phase, IgA rise has higher diagnostic value because it can be detected in 6-7 months in the time when short kinetics of IgE can be useful only for dating of the onset of infection. IgG seroconversion is necessary for diagnostics. Serological diagnostics of prenatal infection is difficult from the time when maternal IgG passively transmit into fetus and interpretations of $\operatorname{IgM}$ and IgA results must be cautious $[1,2,14]$

Histological examination of biological samples shows insufficient reliability if animals are infected by a few parasites. Mouse inoculation is the most reliable method even in the case if detection of cysts in mouse brain demands 40 days. Tachyzoites of virulant strains can be isolated from peritoneal exudate 3-4 days after inoculation. Inoculation of samples in cell cultures (VERO, human fibroblasts) demands specialised laboratories [2]. 
The most reliable method for prenatal diagnostics are PCR, mouse inoculation, cell techniques with usage of amniotic fluid, blood of fetus and peripheral maternal blood in pregnant serologically positive individuals. Utilization of quantitative PCR has developed sensitive, specific and rapid method for detection of T. gondii DNA in amniotic fluid, blood, samples of tissues and cerebrospinal fluid. Molecular methods do not rely on immune response and enable direct detection of parasites in biological samples. They can be used for diagnostics of the disease also in the case if serological tests are not sufficient. In molecular tests are especially useful sequences specific for T. gondii e.g. B1 gene or $529 \mathrm{bp}$ sequence. PCR is very sensitive and is promising technique for obtaining of quantitative results. Molecular methods are used also for genotypization. Molecular methods do not rely on immune response and enable direct detection of a parasite in biological samples. They can be used for diagnostics of a disease even in the case ig serological tests are not sufficient. Sequences specific for T. gondii e. g. B1 gene that repeats in genome 35 times, TGR1 gene, 529 bp sequence are useful in molecular tests. Immediate PCR is very sensitive and it is very promising technique for obtaining of quantitave results [15].

Diagnostics of acute, postnatally achieved primary toxoplasmosis will be based on serological methods. Acute infection caused by T. gondii will be diagnosed by detection of parasite directly using histological and immunological methods, isolation of $T$. gondii from blood, body fluids or tissues on cell cultures. Combination of methods is needed for diagnostics of congenital infection and its late secondary consequences or reactivation of latent infection in immunodeficient patients. In these cases rapid and exact diagnostics is needed to start therapy. PCR method will be used for diagnostics of primary toxoplasmosis in pregnant women to prevent transmission of parasites into fetus but also for diagnostics of toxoplasmosis encephalitis in immunodeficient patients, in which cerebral biopsy is up to now the only diagnostic method and also in the eye form of toxoplamosis. Utilization of quantitative PCR will bring sensitive, specific and rapid method for detection of $T$. gondii DNA in amniotic fluid, in blood, in tissue samples and in cerebrospinal fluid. Specific sequence for T. gondii e.g. B1 gene or 529-bp sequence will be used in molecular tests. They can be used for diagnostics of the disease also in the case, when serological test are not sufficient. Prompt PCR is very sensitive and is promising technique for obtaining of quantitative results [16].

We obtained data about seroprevalence of anti-T. antibodies and occurrence of $T$. DNA from 698 animal serum samples and 256 animla uncoagulated blood samples. For this Examined blood samples were taken from asymptomatic animals, out of which 233 were sheep, 41 goats, 76 cattle, 63 pigs, 91 wild boars, 32 hens, 102 dogs, 39 cats and 21 rabbits. Blood samples were taken from vena jugularis of the beef cattle, sheep and goats, from vena cava cranialis of pigs, form vena cephalica in dogs and cats, vena auricularis in rabbits, and in wild boars and hens the blood was taken immediately after death when animals were bled.

For obtaining serological data about seroprevalence we used two serological tests: complement fixation test (CFT) and ELISA. CFT was performed by the micromodified method after Zástěra et al. [17] published as a supplement to the standard method in Acta 
Hygienica, Epidemiologica et Microbiologica. The test is performed in two steps. The first step resides in the incubation of the mixture of antigen and antibody together with complement (its optimum concentration is tested advance). The second step consists of the detection of free or not fixed complement after its reaction with the immunity complex, while the suspension ready-to-use haemolytic system is used as an indicator. The activity of the complement is determined quantitatively as $50 \%$ hemolysis of haemolytic system. The basic dilution was 1:32 and this titer was considered positive. For diagnosis $T$. antigen (Virion, Switzerland), complement (made from guinea pig serum, Virion, Swizerland; work dilution 1:47.5), T. positive and negative serum (Imuna a. s., the Slovak Republic), and Hemolytic system (ready to use; Virion, Switzerland) were used.

An enzyme-linked immunosorbent assay (ELISA) was carried out for the detection of IgG and IgM antibodies to T. gondii according to the manufacturer's instructions (Test-Line, Czech Republic). In the first step, specific IgG or IgM antibodies in serum were bound to the T. gondii antigen coated on the surface of reagent wells and then, the rabbit anti-species IgG or IgM antibodies (sheep, dog, rabbit, cattle, and wild boar) labelled with peroxidase (Sigma- Aldrich, USA) were applied to the complex formed between the T. gondii antigen and circulating antibodies. After addition of the enzyme substrate, TMB (3,3',5, ' tetramethylbenzidine), the absorbance was read at $450 \mathrm{~nm}$ using a Dynex spectrophotometer (Dynex Technologies, USA). Positive and negative serum controls previously tested by conventional serological test were included on each plate. For each sample, the index of positivity (IP) was calculated according to the schema provided by the manufacturer: $\mathrm{IP}=$ sample absorbance/average absorbance of cut-off serum (cut-off serum is a serum sample which contains antibodies to T. gondii in limiting concentration). Samples with IP $<0.8$ were considered to be negative, samples with IP between 0.8-1.0 were considered to be dubious and samples with IP $>1.0$ were considered to be positive [18].

For molecular analysis total DNA was then purified from white blood cells by using the commercial kit QIAamp DNA Mini Kit (QIAGEN, Germany) according to the manufacturer's instructions. Amplification of the isolated DNA was carried out by the standard PCR and real time PCR method from the T. gondii gene region TGR1E, repeated in the genome 30-35 times, using the specific primers TGR1E-1 and TGR1E-2 [19].

Standard PCR was executed in $25 \mu \mathrm{L}$ reaction volume containing $0.2 \mu \mathrm{M}$ of each primer (TGR1E-1, TGR1E-2), $0.2 \mathrm{mM}$ of each dNTP, $1.5 \mathrm{mM} \mathrm{MgCl}_{2}$ and $2.5 \mathrm{U}$ of Taq DNA polymerase and the reaction was conducted in a thermocycler (Genius, UK) with the following temperature profile: initial denaturation at $94^{\circ} \mathrm{C}$ for $3 \mathrm{~min} ., 40$ cycles of amplification $\left(94^{\circ} \mathrm{C} 1 \mathrm{~min}\right.$., $60^{\circ} \mathrm{C} 1 \mathrm{~min} ., 72^{\circ} \mathrm{C} 1 \mathrm{~min}$.) and final extension at $72^{\circ} \mathrm{C}$ for $7 \mathrm{~min}$. The PCR products were visualized in $3 \%$ agarose gel and stained with ethidium bromide [20]. The final positive PCR product has $191 \mathrm{bp}$ in size.

For quantitative real time cloned T. gondii TGR gene (GenExpress, Germany) diluted to $10^{4}-$ $10^{9}$ was used for the calibration curve. In each reaction, a melting analysis (comparison of the melting temperature (Tm) of PCR products) was determined to differentiate specific and non-specific PCR products. The reaction volume was $25 \mathrm{ul}$, which contained commercial 
FastStart Universal SYBR Green Master (Roche, Germany) and 0.2 uM primers (TGR1-1 and TGR1E-2). Real-time PCR was completed using a thermocycler Line GeneK with the software Line GeneK Fluorescent Quantitative Detection system (BIOER Technology, China). After incubation at $50^{\circ} \mathrm{C}$ for 2 minutes and initial denaturation at $95^{\circ} \mathrm{C}$ for 10 minutes, 40 amplification cycles were performed $\left(95^{\circ} \mathrm{C}\right.$ for $15 \mathrm{~s}, 60^{\circ} \mathrm{C}$ for 1 minute). Melting analysis was carried out at temperatures ranging from $60^{\circ} \mathrm{C}$ to $95^{\circ} \mathrm{C}$, in which the temperature was gradually increased by $0.5^{\circ} \mathrm{C}$ and the period of measurement at individual steps was $15 \mathrm{~s}$. Every PCR run included a control without DNA (containing the reaction mix alone and nuclease-free water).

The examined animals were divided into groups for better understanding of the relationship between the seroprevalence of toxoplasmosis and the age of animals. Each group of examined animals was divided into subgroups according to the age (sheep: female and male lambs up to 4 months of age, rams and ewes; goats: kids - young goats up to 4 months of age, adults - from 7 months of age; pigs: suckling piglets, sows; cattle: calves - up to 6 months of age, heifers, dairy cows; wild boars under 1 year old and adult; Table 1).

\begin{tabular}{|c|c|c|c|}
\hline Animals & $\mathrm{N}$ & Groups & $\mathrm{n}$ \\
\hline \multirow{3}{*}{ sheep } & \multirow{3}{*}{233} & lambs & 40 \\
\hline & & rams & 64 \\
\hline & & ewes & 129 \\
\hline \multirow{2}{*}{ goats } & \multirow{2}{*}{41} & kids & 15 \\
\hline & & goats & 26 \\
\hline \multirow{2}{*}{ pigs } & \multirow{2}{*}{63} & sucking piglets & 20 \\
\hline & & sows & 43 \\
\hline \multirow{3}{*}{ cattle } & \multirow{3}{*}{76} & calves & 25 \\
\hline & & heifers & 10 \\
\hline & & dairy cows & 41 \\
\hline \multirow{2}{*}{ wild boars } & \multirow{2}{*}{91} & young (<1year) & 29 \\
\hline & & adults & 62 \\
\hline \multirow{3}{*}{ dogs } & \multirow{3}{*}{102} & dog shelter & 38 \\
\hline & & professional breeders & 32 \\
\hline & & households & 32 \\
\hline cats & 39 & mixed & 39 \\
\hline rabbits & 21 & mixed & 21 \\
\hline hens & 32 & mixed & 32 \\
\hline Total & 698 & & 698 \\
\hline
\end{tabular}

Table 1. Groups of animals including in serological testing 
For PCR analysis (standard PCR and quantitative real time PCR) each sample was examined by ELISA for detection of IgM and IgG specific antibodies to T. gondii. After serological examination samples were divided into three froups: Group I contained samples only positive to IgM antibodies (acute infection), group II contained samples positive only to IgG antibodies (chronic infection) and group III contained samples without IgM or IgG antibodies (no infection).

Fisher's exact test was used to compare the success of real-time PCR depending on the presence of IgM or IgG antibodies.

During our study we obtained following data in serological analysis. By CFT 698 animals were examined for the presence of overall anti-T. antibodies. A sample with a titre 1:32 and higher was considered to be positive. Out of all specimens, the presence of antibodies to $T$. gondii was detected in 206 cases (29.5\%). out of 233 examined sheep sera 26 (11.1\%) of lambs, $37(15.9 \%)$ of rams and $51(21.9 \%)$ of ewes were positive. The frequency of T. gondii contamination was significantly higher in group of ewes than in other two groups of animals ( $\chi 2$ test: $p<0.01)$. In group of goats, out of 41 serum samples, $5(12.2 \%)$ were positive in subgroup of kids and 7 (14.1\%) in subgroups of adult goats. From 63 examined pigs, only $2(3.2 \%)$ sucking piglets were positive. From 76 examined cattle only $2(2.6 \%)$ of calves were positive for presence of antibodies to T. gondii. From 91 examined wild boars, 18 (19.8\%) exhibited a positive serological reaction to $T$. gondii. The occurrence of anti-T. antibodies was higher in young animals (less than 1 year; 10 positive animals $-10.9 \%$ ) than in adults ( 2 positive animals - 2.2\%). Out of 102 examined dog sera, 17 (16.7\%) were positive in group of dogs from dog shelters, 15 (14.7\%) dogs from professional breeders and 10 $(9.8 \%)$ dogs keeping in households. In group of cats, out of 39 examined sera, 13 (33.3\%) were considered as positive, out of 21 rabbits, 3 (14.3\%) were positive. In group of 32 hens, no positive animal was found (Table 2).

For comparison of CFT and ELISA 102 dog serum specimens were examined for the presence of antibodies to T. gondii by two serological tests (CFT and ELISA). The presence of antibodies to T. gondii was detected in 75 cases (73.5\%). Anti-T. IgG antibodies were found in $51(50 \%)$ by ELISA. Samples positive only with CFT was $39(38.2 \%)$, only in ELISA 14 $(13.7 \%)$, positive in both tests $37(36.3 \%)$ and negative in both tests $12(11.8 \%)$. The titres of latent infection (1:8 - 1:128) in CFT were recorded in 75 dogs: 13 dogs (12.7\%; 1:8), 20 dogs (19.6\%; 1:16), 20 dogs (19.6\%; 1:32), 20 dogs (19.6\%; 1:64) and 1 dog (1\%; 1:128). The prevalence of acute infection (1:256 and higher) was recorded in $1 \mathrm{dog}$ (1\%; 1:256). The coincidence of CFT and IgG antibodies was recorded in 37 samples (36.3\%). Comparison of detection of antibodies by these two tests was statistically significant $(\mathrm{p}<0.001$, Figure 2$)$.

In molecular analysis by standard PCR and quantitative PCR at first IgM antibodies which appear at the beginning of infection and which are characteristic for acute infection were detected in 45 of $256(17.6 \%)$ by ELISA. IgG antibodies which corresponded with chronic infection were detected in 120 of 256 (46.8\%). In 91of 256 (35.5\%) animals neither IgM nor IgG were detected by ELISA. The occurrence of $\operatorname{IgM}$ or $\operatorname{IgG}$ antibodies in each species is summarized in Table 3. 


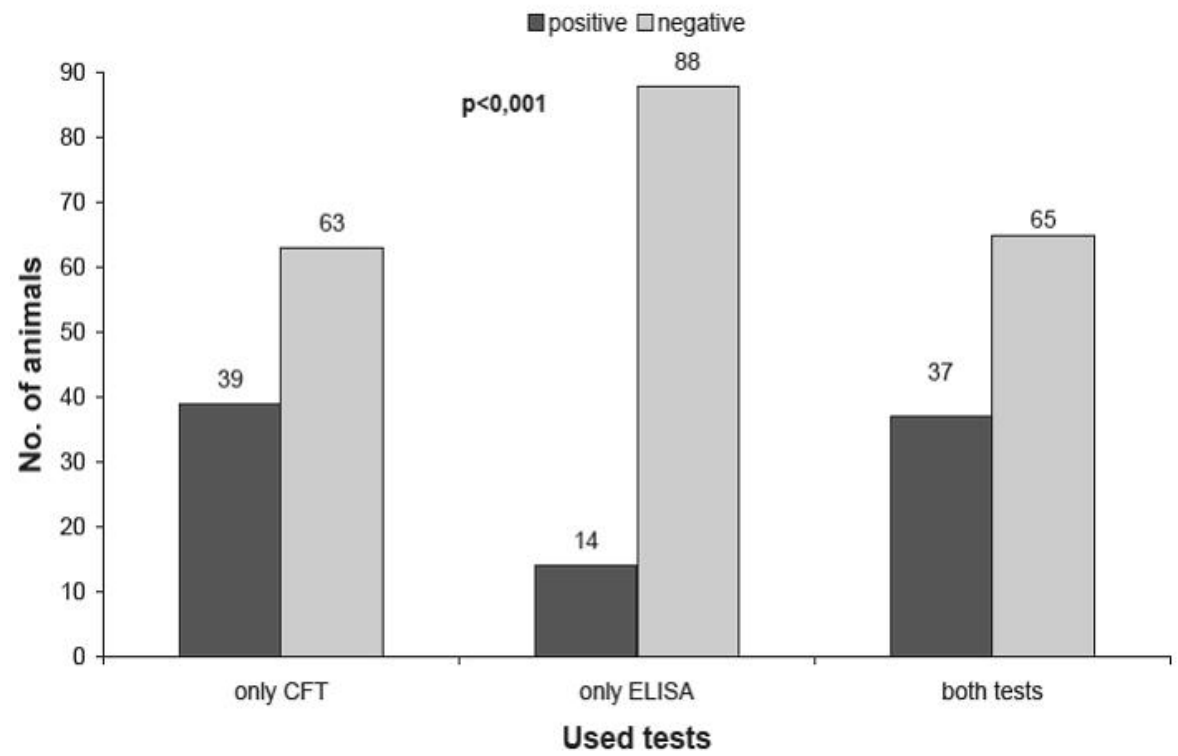

$\mathrm{P}^{*}$ value were obtained by comparing results obtained by CFT to results obtained only by ELISA

Figure 2. Number of animals positive only in CFT, only in ELISA and in both tests $(\mathrm{p}<0.001)$

\begin{tabular}{cccc}
\hline Animals & $\mathrm{n}$ & Groups & $\mathrm{N} / \mathrm{SP} \%$ \\
\hline \hline \multirow{2}{*}{ sheep } & \multirow{2}{*}{233} & lambs & $26 / 11.1$ \\
& & rams & $37 / 15.9$ \\
goats & 41 & ewes & $51 / 21.9^{*}$ \\
& & kids & $5 / 12.2$ \\
pigs & 63 & goats & $7 / 14.1$ \\
& & sucking piglets & $2 / 3.2$ \\
cattle & 76 & sows & $0 / 0$ \\
& & calves & $2 / 2.6$ \\
wild boars & 91 & heifers & $0 / 0$ \\
& & dairy cows & $0 / 0$ \\
dogs & 102 & young $(<1$ year & $10 / 10.9$ \\
& & adults & $2 / 2.2$ \\
cats & 39 & dog shelter & $17 / 16.7$ \\
rabbits & 21 & professional breeders & $15 / 14.7$ \\
hens & 32 & households & $10 / 9.8$ \\
Total & 698 & mixed & $13 / 33.3$ \\
\hline \hline
\end{tabular}

$\mathrm{n}$ - number of examined samples; $\mathrm{N}$ - number od positive samples; SP - seroprevalence (\%)

Table 2. Occurrence of overall antibodies to $T$. gondii by CFT in different animal species 


\begin{tabular}{cccccc}
\hline \multirow{2}{*}{ Animals } & \multicolumn{2}{c}{ IgM } & \multicolumn{2}{c}{ IgG } & \multirow{2}{*}{ Negative } \\
& $\mathrm{N} / \mathrm{n}$ & $\%$ & $\mathrm{~N} / \mathrm{n}$ & $\%$ & 0 \\
\hline \hline sheep & $27 / 50$ & $54 \%$ & $23 / 50$ & $46 \%$ & 8 \\
cattle & $4 / 32$ & $12.5 \%$ & $20 / 32$ & $62.5 \%$ & 5 \\
rabbits & $7 / 36$ & $19.4 \%$ & $24 / 36$ & $66.6 \%$ & 68 \\
wild boars & $5 / 9$ & $15.5 \%$ & $18 / 91$ & $19.8 \%$ & 10 \\
dogs & $2 / 47$ & $4.3 \%$ & $35 / 47$ & $74.5 \%$ & $\mathbf{9 1}$ \\
\hline \hline Total & $\mathbf{2 5 / 2 5 6}$ & $\mathbf{1 7 . 6} \%$ & $\mathbf{1 2 0 / 2 5 6}$ & $\mathbf{4 6 . 9 \%}$ & \\
\hline
\end{tabular}

$\mathrm{N}$ - number of positive samples; $\mathrm{n}$ - number of examined samples; \% seroprevalence

Table 3. Occurence of IgG and IgM antibodies to T. gondii by ELISA in different animal species

According to the serological results animals were divided into three groups: animals with suspicion of acute (group I, n=45) or chronic toxoplasmosis (group II, n=120) and without infection (group III, n=91). For statistical analysis, we considered group I (acute infection, IgM positive) and group II (chronic infection, IgG positive).

By standard PCR the presence of DNA T. gondii was detected in ten samples of noncoagulated blood (6 sheep, 1 wild boar and 3 rabbits) with the DNA product length $191 \mathrm{bp}$ (Figure 3).

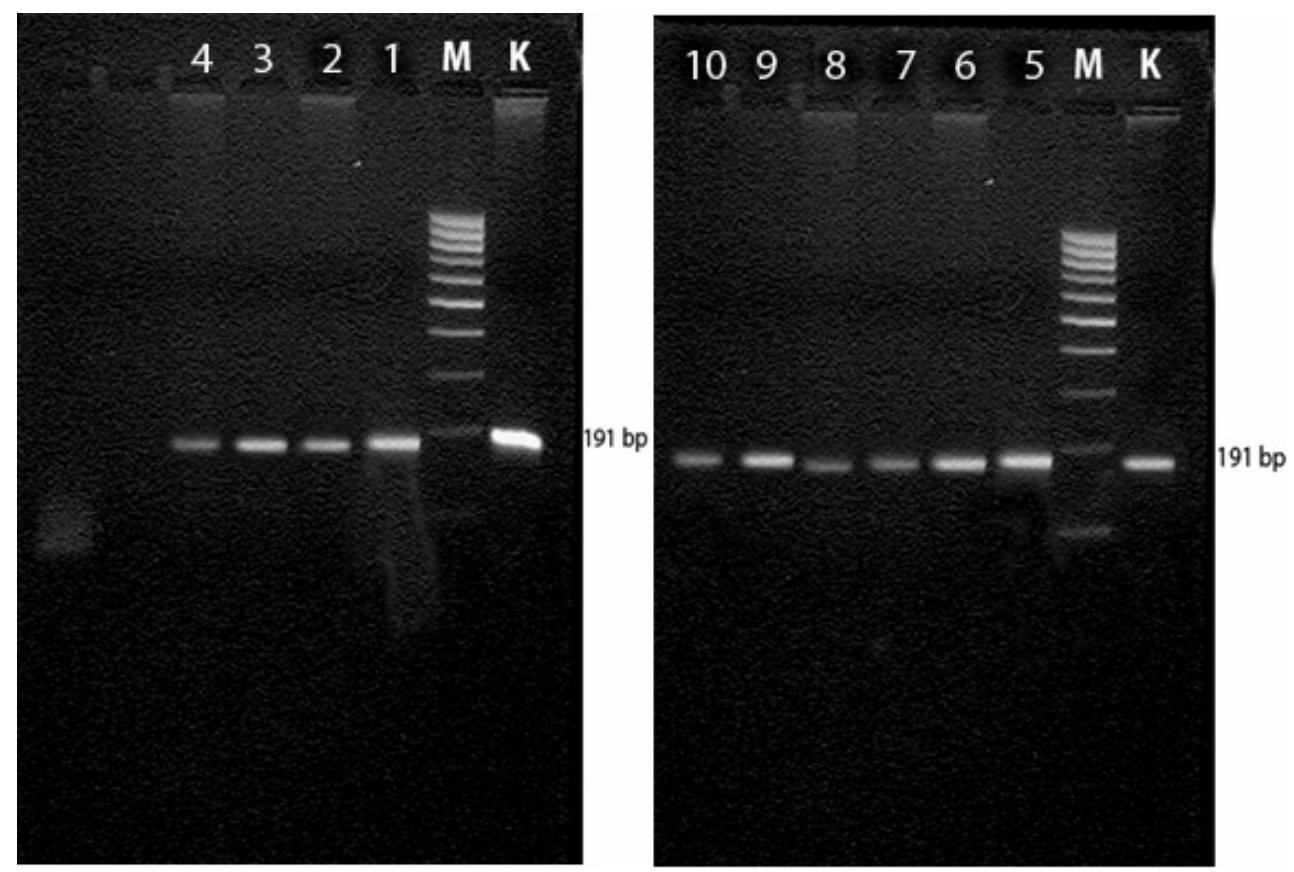

Figure 3. PCR fragment of $T$. gondii DNA (191 bp) in a $3 \%$ agarose gel. K: positive control, M: marker of size (100bp plus DNA ladder, Fermentas, Germany); lane 1: positive wild boar sample, lanes 2-4: positive rabbit samples; lanes 5-10: positive sheep samples 
Using quantitative real time PCR the presence of DNA T. gondii was detected and the number of their copies quantified in the 256 non-coagulated animal blood samples. Using real time PCR T. gondii DNA was detected and quantified in ten samples of non-coagulated blood (6 sheep, 1 wild boar and 3 rabbits; Table 4). For animals presenting acute toxoplasmosis (group I), the presence of T. gondii DNA was detected in 9 of $45(20 \%)$, whereas in chronic group (group II) only one sample was positive $(1 / 120 ; 0.8 \%)$. In group III which contained animals without IgM or IgG antibodies no DNA of T. gondii (0/91) was detected by real time PCR. The proof of DNA by real time PCR in IgM positive samples was statistically significant in comparison to IgG positive samples $(\mathrm{P}<0.0001)$.

Standards with the known dilution of $T$. DNA were used to determine the detection limit of a modified real time PCR and to create a calibration curve that ranged from $10^{9}$ to $10^{4}$ copies of T. DNA. The correlation coefficient of the calibration curve was 0.998. As SYBR Green a fluorescent dye, was used as a detection system, a melting analysis was a part of the realtime PCR to distinguish between specific and non-specific products. During the melting analysis the melting temperature (Tm) of a positive control and positive samples was $84{ }^{\circ} \mathrm{C}$ (Figure 4). In quantifying the examined samples within a 40-cycle protocol for the real time $\mathrm{PCR}$, the number of copies detected in the positive samples ranged from $1.07 \times 10^{2}$ to $1.49 \mathrm{x}$ $10^{5}$ (Table 5).

\begin{tabular}{lcccc}
\hline & \multirow{2}{*}{} & \multicolumn{2}{c}{ Real time PCR } & \multirow{2}{*}{ P value } \\
& & positive & negative & \\
\hline \hline Group I $(\operatorname{IgM}+)$ & 45 & 9 & 36 & $<0.0001^{*}$ \\
Group II $(\operatorname{IgG}+)$ & 120 & 1 & 119 & - \\
\hline \hline
\end{tabular}

Group I-acute toxoplasmosis; Group II-chronic toxoplasmosis; $P^{*}$ value were obtained by comparison of the proof of $T$. DNA by qPCR in group I (acute infection, IgM positive) and group II (chronic infection, IgG positive)

Table 4. Relation between the presence of $T$. gondii DNA and serological results

\begin{tabular}{lll}
\hline Sample & Number of copies & Group \\
\hline \hline Sheep 1 & $5.92 \times 10^{4}$ & IgM+ \\
Lamb 1 & $1.49 \times 10^{5}$ & IgM+ \\
Sheep 3 & $3.67 \times 10^{4}$ & IgM+ \\
Sheep 4 & $5.75 \times 10^{2}$ & IgM+ \\
Sheep 5 & $3.89 \times 10^{4}$ & IgM+ \\
Sheep 6 & $2.56 \times 10^{3}$ & IgM+ \\
Wild boar & $1.05 \times 10^{5}$ & IgM- \\
Rabbit 1 & $1.07 \times 10^{2}$ & IgM+ \\
Rabbit 2 & $2.09 \times 10^{2}$ & IgM+ \\
Rabbit 3 & $3.17 \times 10^{2}$ & IgM+ \\
\hline
\end{tabular}

Table 5. The number of $T$. gondii DNA copies in the examined samples in a $25 \mu \mathrm{l}$-volume 


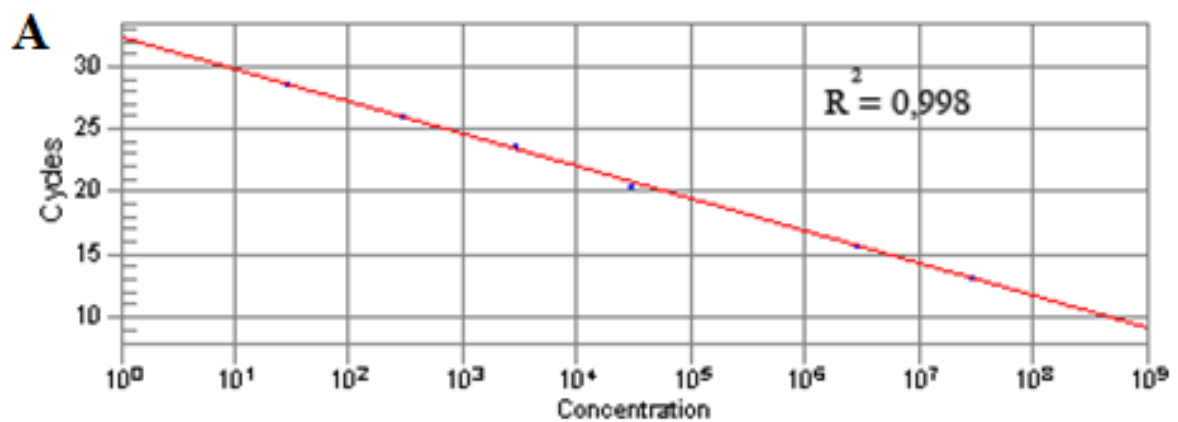

B
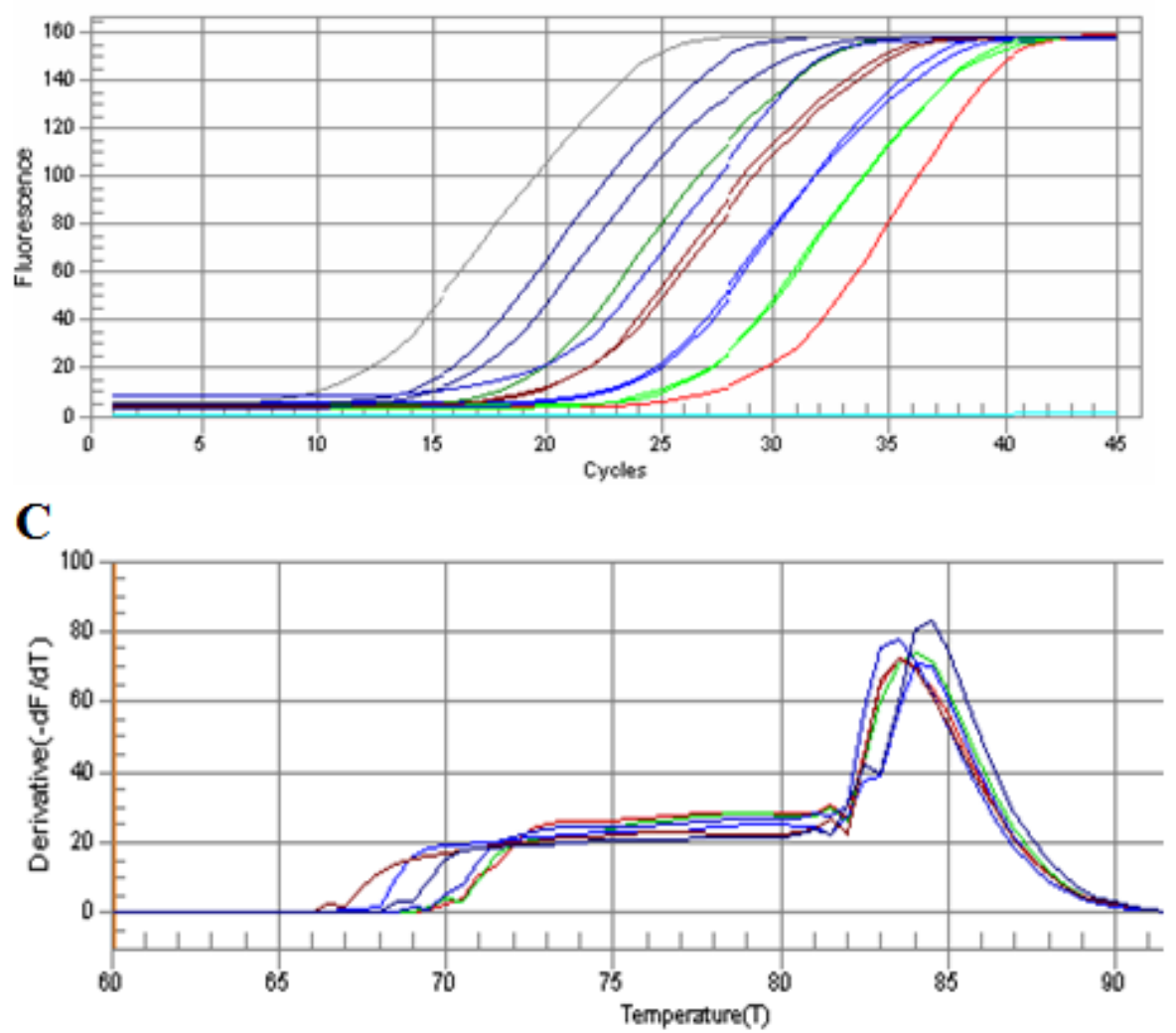

Figure 4. Quantitative real time PCR - A-Calibration curve; B - Samples; C - Melting analysis

The diagnosis of toxoplasmosis may be established by serological tests, polymerase chain reaction (PCR), histological demonstration of the parasite and/or its antigens (i.e. immunoperoxidase stain), or isolation of the organism. The serological tests are able to show the presence of IgM antibodies which can represent the acute infection as well as these IgM antibodies can be residual. Avidity tests may help in this setting by distinguishing between 
IgG of high and low affinity, corresponding to either chronic or acute toxoplasmosis. Results of serological tests don't reflect the course of infection. The presence of specific serum antibodies is possible to detect in organism of each potential host who come in the contact with the pathogen. Based on the serological prevalence in the population is possible to suppose only the certain relationship between population and morbidity. The advantage of serological tests is that specific antibodies can be detected two week before histological proof of parasite in pathological lesions and 4 weeks before the molecular proof of parasites in infected tissues. The positive serological result is only indicative of infection, whereas direct detection of $T$. gondii in blood or other clinical samples categorically confirms the parasite presence in the organism $[15,21]$. Several indirect methods have been proposed for the detection of antibodies to $T$. in animals, generally in samples of serum and plasma. In addition, thoracic fluid of aborted fetuses, milk and samples of fluid obtained by freezing and thawing portions of muscular tissue (meat juice) can be tested as well for antibodies. However, data from different studies may not always be directly comparable due to discrepancies in the procedures used for the detection of antibodies. For example, the modification of protocols, the different strains of $T$., and the different cut-off points of tests. Not all assays are suitable for every animal species and cross reactions with antibodies to related parasites may result in false positives. Serological methods of $T$. diagnostics are still very important. They are required for quick and reliable results about epizootological situations in countries because of the zoonotic character of $T$. infection. Toxoplasmosis belongs to the majority of prevalent infections in livestock. The prevalence of this protozoan disease has been demonstrated by studies carried out to detect antibodies to T. gondii in farms of domestic animals in other European countries. It can be demonstrated by Fusco et al. [22] and Masala et al. [23] who have detected the presence of antibodies to T. gondii in their work using serological methods in sheep and goats. Fusco et al. [22] examined 117 flocks of sheep bred in pastures in the region of Campania, southern Italy. Blood and milk specimens were collected from 10 adult sheep from each of the flocks (sheep aged more than 18 months). A total of as many as 1,170 sheep were examined. The serum specimens were examined for the presence of IgG antibodies by means of an IFAT method (an indirect immunofluorescence antibody test). Out of the 1,170 examined sheep, 333 specimens were positive to T. infection (28.5\%). Between 1999 and 2002 Masala et al. [23] analyzed 9,639 serum specimens and 815 abortion specimens (670 aborted fetuses and 145 placentas) from 964 sheep and goat farms in Sardinia. The collected sera were examined for the detection of IgG and IgM specific antibodies to T. gondii using the indirect immunofluorescence method. Specific IgG antibodies were diagnosed in 652 sheep (9\%). In France, the presence of specific IgG antibodies to T. gondii was detected in $22 \%$ of lambs and $65.6 \%$ of gravid sheep; in Sicily, the seroprevalence ranges between 70 and $90 \%$; in Switzerland, it is in approximately $58.6 \%$ of sheep; while in Germany, it is only $19.1 \%$ [24]. Seroprevalence of toxoplasmosis were determined in 87 goats of the eastern Slovakia. From these animals antibodies were found out in 43 goat sera $(49.43 \%)$. Statistically significant correlation $(P<0.0001)$ was found between the prevalence of antibodies against $T$. gondii and animal age in comparing age groups - goats up to 36 months of age and above 37 months of age [25]. In view of the prevalence of toxoplasmosis in pigs in the Czech Republic, an interesting result occurred 
from the examination of 787 pigs in 1999 . They came from a modern large-capacity breeding farm in southern Bohemia. They were all examined using a complement fixation test and out of a total of 787 animals, the antibodies were detected only in 4 cases [26]. In the Slovak republic were detected antibodies to T. gondii by ELISA in 840 serum samples of pigs and 21 samples (2.5\%) were considered as positive [27]. Pleva et al. [28] published the results of examination of 582 serum samples of cattle in 1996 and in no sample antibodies against $T$. gondii was found. In 2008 were examined 85 samples of cattle from Slovakia by ELISA. AntiT. antibodies were detected only in 2 (2.35\%) samples [29]. In 2009 they examined 312 serum samples of cattle from Slovakia. From all examined samples they found out the presence of antibodies to T. gondii in 31 (9.94\%) samples. The risk of infection of domestic animals with T. gondii is very high. Among the measures that can be taken are keeping meat-producing animals in captivity on farms during the whole feeding period, maintaining the stables without rodents, birds or insects, paying closer attention to feeding the animals with noncontaminated fodder. By taking these measures it is possible to run farms with low prevalence of toxoplasmosis [30]. Wild boar is an autochthonous species of leafy exploitation of the Slovak republic. Due to the agricultural exploitation of landscape, disseminating of maize production, intensive forest management and low mortality of piglet during snow and absence of big carnivores, the wild boar population started to increase from the second half of the $20^{\text {th }}$ century. The rising number of wild boars causes economic losses and may represent a source of dissemination of different diseases. Tissue cysts of $T$. gondii in meat of different game species are potential sources of human infection [31]. The overall T. gondii seroprevalence in wild boars was $19.8 \%$ in the present study and was significantly higher in young animals (37.9\%). This corresponds to the fact that toxoplasmosis is most commonly seen in young animals, especially in neonates and in immuno-compromised animals. Toxoplasmosis in young animals causes severe damage such as intra-uterine growth restriction, icterus, hepato-splenomegaly, myocarditis, pneumonitis, and various rashes. Neurologic involvement, often prominent, includes chorio-retinitis, hydrocephalus, intracranial calcifications, microcephaly, and seizures [31]. In Europe, anti-T. gondii antibodies were found in $8.1 \%(26 / 320)$ or $38.5 \%$ (5/13) of wild boars from Slovakia [32], 26.2\% (148/565) from the Czech Republic [33], 16.6\% (2/12) from Bulgaria [34] and 21.1\% (11/52) from Eastern Poland [35]. In France Richomme et al. [36] tested 148 sera and tissues of wild boars for $T$. infection from two French regions, one continental and one insular. Antibodies to T. gondii were found in $26(17.6 \%)$ of 148 wild boars using the modified agglutination test (MAT, positivity threshold: 1:24). Seroprevalence was 45.9\% when considering a threshold of 1:6. Hearts of individuals with a positive agglutination (starting dilution 1:6) $(\mathrm{n}=60)$ were bioassayed in mice for isolation of viable T. gondii. In total, 21 isolates of T. gondii were obtained. In other wildlife from France Aubert et al. [37] T. gondii antibodies were found in 14 of 19 (73.7\%) red foxes, with titers between 1:25 and 1:6400 and parasite isolation was successful in 9/13 seropositive animals (69.2\%). Thirty-six of the 60 roe deer $(60 \%)$ showed antibodies with titers between 1:6 and 1:6400. Thirty-three bioassays were performed, 12 isolates were obtained from animals with antibodies titers between 1:25 and 1:6400. T. gondii antibodies were found in 4 of 24 red deer (17\%) with titers of 1:6 (2), 1:10 (1) and 1:25 (1) and a viable parasite was isolated from the heart of one red 
deer with a titer of 1:6. No parasite was isolated from fallow deer with only one positive with a titer of 1:25. T. gondii antibodies were found in 7 of 31 mouflons (23\%) with titers between 1:6 and 1:6400 and the isolate was detected only in one samples. The brown hare $(L$. europaeus) is a common species of wild mammals in Europe where they are extensively hunted. They detected T. gondii antibodies in only $9 \%$ of sera from brown hares but failed to isolate viable parasites. In households animals (such as cats, dogs and rabbits) T. gondii represent a health hazard and can have the impact for the owners. Toxoplasmosis of pet animals as dogs, cats and rabbits is also important source of infection. In dogs, toxoplasmosis is a rare primary disease of dogs. Martins and Viana [38] highlight the importance of dogs in the epidemiological chain of the disease, through the habit of ingesting, and rolling in cat feces, thus permitting transmission of oocysts by contact of the contaminated hide. Lindsay et al. [39] demonstrated that after ingestion of T. gondii nonsporulate oocysts, these could pass through the intestinal tract of dogs, and be excreted in their infectious stage, re-enforcing the theory that dogs act as mechanical vectors of oocysts. The sources of the contamination by oocysts are mainly moist and shady places with the occurrence of cats where are suitable conditions for surviving of oocysts for a long period in the external environment [40]. Serological diagnosis of $T$. gondii infections in dogs and cats has been evaluated by many investigators. The tests used include the Sabin-Feldman, the complement fixation, the indirect haemagglutination, the direct agglutination, the indirect fluorescent antibody and the enzyme immunoassay. The demonstration of antibodies by these serological tests just indicates previous infection by T. gondii. A laboratory diagnosis defined to toxoplasmosis-disease requires the demonstration of high titers of specific antibodies and increasing levels in two serum samples taken 2 to 4 weeks apart. The prevalence of antibodies to T. gondii was determined in sera from dogs in Grenada, West Indies. Using a modified agglutination test, antibodies to T. gondii were found in 52 (48.5\%) of the 107 dogs, with titers of 1:25 in 17, 1:50 in 19, 1:100 in 7, 1:1,600 in 5, and 1:3,200 or higher in 4 [41]. Lopes et al. [42] reported a serological survey of antibodies to T. gondii in domestic cats from northeastern Portugal, by means of the modified agglutination test. Three cats had titres of 20 (3.9\%), 18 had titres of 40 (23.7\%) and 55 animals had titres of $\geq 800$ $(72.4 \%)$. Infection levels were also significantly different between cats that lived totally indoors $(7.7 \%)$ and those that had access to outdoors (45.4\%), as well as between cats living alone $(13.8 \%)$ and those that had contact with other cats $(39.4 \%)$. Seroprevalence values in cats fed only commercial canned or dried food (22.9\%) and animals whose diet included raw or undercooked viscera and/or meat $(53.5 \%)$ were also significantly different. Age, habitat and diet were identified as risk factors for the feline $T$. gondii infection by logistic regression analysis. Some control measures are suggested based on these findings [42]. Samples of serum taken during 1986 and 1987 from 244 pet cats, 303 dogs, were screened by enzyme-linked immunosorbent assay (ELISA) for antibodies to T. gondii $42 \%$ of cats, $23 \%$ of dogs examined were found seropositive [43]. Five hundred and sixty seven sera of healthy house cats were examined for the presence of anti- $T$. antibodies by indirect immunofluorescence assay. Twenty-five percent of cats tested positive for IgG and/or IgM. Seroprevalence increased with age from $2 \%$ below 12 months of age up to $44 \%$ at age 7 . 
These results suggest that $T$. gondii infections are common in house cats and that there is a high chance for a negative cat to seroconvert in its second life-year [44]. Sera of 413 dogs and 286 cats from the Czech Republic were tested for antibodies to T. gondii by the indirect fluorescent antibody test. The IgM antibodies to T. gondii were found in $10 \mathrm{dogs}(2.4 \%)$ and 8 cats (2.8\%); IgG antibodies were found in 107 dogs (25.9\%) and 126 cats (44.1\%). Of the dogs, the most exposed group were pet dogs, followed by police dogs; no antibodies were found in laboratory dogs. No statistically significant differences in prevalence were observed between clinically healthy $(n=115)$ and diseased pet dogs $(n=80)$; compare $0.87 \%$ and $1.25 \%$ for IgM, and $33.9 \%$ and $33.75 \%$ for IgG, respectively. Although T. gondii is a common parasite in domestic cats and dogs, the clinical importance is low [45]. Figueroa-Castillo et al. [46] determined antibodies to $T$. gondii by indirect ELISA in serum samples from domestic rabbits from 3 rabbit farms in Mexico. Antibodies to T. gondii were found in 77 $(26.9 \%)$ of 286 animals. On the farm with the higher rearing standards, the seroprevalence was $18.7 \%$, whereas on the farm with medium standards and another managed by a family, seroprevalence was 39.7 and $33.3 \%$, respectively. This report is the first report concerning the prevalence of antibodies to T. gondii in rabbits from Mexico. Although the prevalence found in the present study is within the range reported for other countries, 2 of the farms revealed a relatively high prevalence, which was probably associated with the presence of cats inside rabbit houses [46]. In term of infection spread is important animal breeding, contact with another animal and composition and processing of feed. In animals keeping in households the most important role is composition and processing of food. The feeding of raw or undercooked meat or offal plays the main role in spreading of infection in household animals. The important part of rabbit feeding is fruits and vegetables. The fruits and vegetables contaminated with infected soil and inadequately washed presents the important source of $T$. infection with infected oocysts. The role of domestic rabbit in epidemiology of toxoplasmosis in humans has not been established in detail, but is probably important. Although some authors treat this role marginally, others place the rabbit among the animal species posing a major source of infection for man [47]. Ishikawa et al. [48] described the case of cervical toxoplasmosis transmitted from rabbit to man. Nevertheless, there is a lack of controlled epidemiological studies on the degrees of a correlation between the prevalence of toxoplasmosis in rabbits and in humans having contacts with these animals [48].

Among laboratory diagnostic techniques, a complement fixation test is one of the most frequently employed techniques for detecting antibodies to T. gondii. Results acquired in complement fixation tests in examinations for the presence of antibodies against T. gondii antigens in the serum specimens of infected animals facilitate the interpretation of such results. The level of overall antibodies in a CFT significantly correlates with the dynamics of IgM and IgA antibodies. A titre of 1:256 - 512 is significant for the acute phase of infection, whereas titres below 1:128 point to the chronic or latent course of the disease. With respect to the determination of $T$. infection in a serological examination, a CFT is of greater informative value in comparison to the same requirement related to $\operatorname{IgG}$ antibodies. Specific IgG antibodies detected by ELISA are a reliable substitution of quantitative results that can be assessed by CFT but due to the fact that the dynamics of CFT antibodies is more significantly associated with course of the disease, the assessment of the phase of infection 
must be supported also by parallel examination of IgM or IgA antibodies [49]. So CFT should be the first part of basic examination procedures in the laboratory diagnosis of toxoplasmosis. The complement fixation test is the basic method in the diagnosis of toxoplasmosis. Despite its standard and reproducible results, it is rarely used in routine diagnosis of toxoplasmosis where the detection of IgG by means of ELISA is widely used. Our results suggested that CFT is reliable indicator of $T$. infection because was found a correlation between CFT and IgG ELISA. In our study were positive $36.3 \%$ of samples in both tests and $38.2 \%$ of examined samples were positive only in CFT. A significant differences in results obtained by CFT and ELISA could be influenced also by the higher positive titer established in ELISA (1:100). Also it is possible that this difference is due to the fact that by CFT we detected overall antibodies (characteristic for acute and chronic reaction) but by ELISA we detected only IgG antibodies (characteristic mainly for chronic infection) not overall antibodies. Ondriska et al. [49] analyzed 1705 samples of serum from human patients by CFT and IgA, IgM and IgG ELISA. They found a dependence when comparing the CFT titres and concentrations of IgG antibodies $(r=0.549, \mathrm{p}<0.05)$. A higher correlation was found when compared the CFT titres and concentrations of IgA antibodies $(\mathrm{r}=0.956)$ [49]. The limiting criterion for the evaluation of laboratory results is the assessment of the limiting cut-off value for the substance being assessed in reaction. In view of individual immunoreactivity and reactivity implying from organ localization of infection, the determination of CFT value is problematic and therefore it is more suitable to use the term of "diagnostically significant value". For example, while Feldner [50] considers CFT titer equal to or over 1:10 in the correlation with positive IgM antibodies to be characteristic for acute infection, according to Catár et al. [51] this titre is more frequent in latent infections. Flegr and Havlíček [52] consider the titres as high as 1:128 to be significant. The titres equal to or below 1:64 according to these authors are detected mostly in patients with chronic or latent infection. In our study were found mostly titres characterized for latent infection and only one sample was in titer 1:256 responsible for acute infection.

Gene amplification methods (PCR, LCR, NASBA, etc.) are now used widely in the diagnosis of infectious diseases. Key advantages are their relative speed, the potential to detect very low numbers of pathogens (or, more precisely, specific nucleic acid sequences from pathogens) and the ability to discriminate accurately at the species or sub-species level. In the case of non-persistent pathogens that are cleared from the body, a positive PCR finding is usually significant. The diagnosis of toxoplasmosis by PCR, however, is complicated by the fact that the parasite persists (principally in heart, brain and skeletal muscle in the form of quiescent tissue cysts) for many years after active infection has ceased. Thus, the presence of $T$. gondii in such tissues does not necessarily equate to active toxoplasmosis. Therefore is possible to find discrepancy between the serological results and results of molecular methods [2]. Molecular tests detecting circulating parasites would be helpful in the final diagnosis. Direct methods, such as PCR need biopsy samples [2,53]. Methods of sampling of the brain and other internal organ tissues in animals are not as sophisticated as in humans. This is particularly true of large animals meat-producing animals (e.g. cattle, sheep, goats and pigs), which pose the greatest risk of toxoplasmosis transmission to humans. In our study we decided to use blood as the main sample for isolation and detection of $T$. gondii 
DNA. The purpose of this study was to find out the relationship between the phase of infection acute or persist and the ability of quantitative PCR to detect DNA T. gondii in circulating leukocytes in the blood stream. Our study has shown that PCR analysis of animal blood can only detect DNA of T. gondii in acute phase of infection. At this time in infection parasites are hidden within leukocytes and that are circulating in the blood stream. At this stage, we are able to capture parasites and isolate DNA of T. gondii. After initiation of the chronic phase, parasites are hidden within cysts in the tissues and organs of the animals and it is not possible to detect their presence in the blood. DNA of T. gondii was confirmed in 10 animals from the total of 256 animals sampled. Of the ten PCR-positive animals DNA was detected in nine individuals with ongoing acute phase of infection (confirmed by ELISA). Hitt and Filice [54] detected T. gondii DNA in 12 of 32 (37\%) rabbit blood samples by PCR. The decreased PCR sensitivity in blood samples was believed to be influenced by localization of leukocytes. In their study leukocytes in heparinised blood were not localized in leukocyte layer but they were distributed widely, mostly in erythrocyte layer. Therefore, the choice of the genome area which is amplified is important for efficiency of PCR analysis. Hitt and Filice believed that the B1 gene of genome enhanced the sensitivity of PCR techniques from blood samples [54]. Other investigators have been unable to detect T. gondii DNA in bone marrow from humans or whole blood from mice with toxoplasmosis. Heme, heparin, and other poorly characterized substances have been reported to decrease sensitivity [55]. Kompalic-Cristo et al. [56] examined 183 buffy coat samples from serologically examined patients, of the IgM seropositive patients $48.6 \%$ presented parasiteamia proven by PCR, whereas $3.6 \%$ positivity was achieved in individuals with chronic infection [56]. Lamoril et al. [57] examined 19 patients with confirmed cerebral toxoplasmosis and in only three cases samples were PCR positive. In the case of generalized toxoplasmosis, the lymph nodes, liver, spleen could be affected by infection and in this situation there is higher possibility to detect $T$. DNA by PCR [57]. Truppel et al. [58] examined Capybaras, Hydrochaeris hydrochaeris, by serological test and also examined lymph node, liver, spleen, heart and blood samples for the detection of T. DNA. T. DNA has been detected in the same samples of liver and blood [58]. In general PCR techniques are less sensitive in diagnosis of toxoplasmosis. One of the main problems is missing standardization of PCR performance according to laboratory conditions. The other problem is the kind of tested tissue (e.g. blood, liver, spleen, cerebrospinal fluid etc.). Each study has different sensitivity in the PCR with different tissues. Comparison studies, that compare PCR using different tissue samples give us the better view on sensitivity of PCR and help us to choose the best tissue samples with regard to easy and the least invasive for the animals.

\section{Conclusion}

All mammals and birds that are consumed by humans may serve as intermediate hosts for T. gondii and thus may be a potential source of infection for humans. In the life cycle of $T$. gondii are three infectious stages i.e. tachyzoites, bradyzoites contained in tissue cysts and sporozoites contained in sporulated oocysts. All three stages are infectious for both intermediate and definitive hosts which may acquire a $T$. gondii infection horizontally by oral ingestion of infectious oocysts from the environment, horizontally by oral ingestion of 
tissues cysts contained in raw and undercooked meat or primary offal of intermediate hosts and vertically by transplacental transmission of tachyzoites [1]. From the animal point of view, meat-producing animal represent the source of tissue cysts for humans. Tissue cysts of T. gondii have a high affinity for neural and muscular tissues. They are located predominantly in the central nervous system, the eye, as well as skeletal and cardiac muscles. Therefore, tissue cysts of T. gondii contained in meat, meat derived products or offal may be importance sources of infections for humans. Although the potential for transmission of the parasite to humans via food has been known for several decades, it is not known which routes are most important from a public health point of view. It is likely that transmission of the parasite to humans is influenced not only by the potential contamination of various food sources, but also by the individual behavior of consumers in different ethnic groups and geographical regions. Most current methods for detection of $T$. gondii in meat-producing animals, in products of animal origin, or in the environment are insufficient because they do not allow quantification of infectious stages. Hence, most studies report only qualitative data from which it is difficult to assess the true risk of infection in individual cases. There is a need for quantitative data so that efficient strategies to reduce food-borne transmission of T. gondii to humans can be developed [59]. For public health purposes it is important to note that the organotropism of $T$. gondii and the number of tissue cysts produced in a certain organ vary with the intermediate and host species. Therefore, not all animals used for human consumption are of the same public health significance. In livestock, T. gondii tissue cysts are most frequently observed in various tissues of infected pigs, sheep and goats, and less frequently in infected poultry, rabbits, dogs and horses. By contrast, tissue cysts are found only rarely in skeletal muscles of cattle or buffaloes. Usually, the consumption of raw or undercooked pork or mutton is regarded as a major factor in food-borne transmission to humans. However, it is possible to significantly reduce the risk of $T$. gondii infection in livestock using intensive farm management with adequate measures of hygiene, confinement and prevention. These measures include: keeping meat-producing animals indoors throughout their life-time; keeping the sheds free of rodents, birds and insects; feeding meat-producing animals on sterilised food and controlling access to sheds and feed stores, i.e., no pet animals should be allowed inside them. Using such preventive measures, it is economically possible to produce pigs and poultry free of T. gondii infection. By contrast, production of free-ranging livestock will inevitably be associated with T. gondii infection. Animals such as sheep and goats kept on pastures have an increased risk of infection due to contamination of the environment with sporulated oocysts. Such animals show high levels of seropositivity in many areas of the world, i.e. up to $92 \%$ and $75 \%$, respectively [1]. This is of particular importance because tissue cysts have been found in many edible parts of sheep $[60,61]$ and small ruminants are important in both milk and meat production throughout the world. Seropositivity is distinctly lower and more varying in horses, rabbits and poultry. This may reflect epidemiological factors such as different types of confinement, hygiene of stables and different types of feed. By contrast, seropositivity is usually high in dogs, indicating their continuous exposure to a natural environment and the cumulative effect of age. All of these animals may harbour a considerable number of tissue cysts in their organs, including 
skeletal muscles, and thus have importance in food-borne transmission to humans who consume their meat $[1,62]$.

Tissue cysts of T. gondii in venison and other meat of wild animals, including hares, wild boars, deer and other cervids, kangaroos and bears are other potential sources of infection for humans [1,63]. In addition to higher environmental pressure of infection, there is a cumulative effect of age in many wild animals that results in a very high prevalence of infection. Some wild animals, such as Australian native marsupials, have evolved in the absence of $T$. gondii until cats were introduced to their environment only a few hundred years ago. As a consequence, these animals are highly susceptible to the parasite. Although seropositivity of $T$. gondii infection in marsupials is usually lower than in placental mammals, kangaroo meat in particular has been recognised as a potential source of infection for humans, because it is very lean with little fat and, thus, is usually consumed rare or undercooked [64]. It is important to know that seropositivity of meat-producing animals does not necessarily reflect the risk that those animals pose for their consumers. For example, the meat of cattle and buffaloes rarely contains tissue cysts, although in some area more than $90 \%$ of these animals are seropositive for T. gondii. By contrast, seropositive pigs, sheep and goats can be assumed to harbor large number of tissue cysts in their meat $[63,65]$. On the basis of the abovementioned facts, it is assumable that the prevalence of the infection with T. gondii mainly in livestock is closely related to the method of breeding these animals. In animals which are bred extensively and are grazed in pastures, the risk of infection is higher than in animals bred on farms with no contact with the outside environment. While grazing, the animals are exposed for long periods to the possibility of infection from the environment. Infected green fodder, soil and water are the most frequent sources of infection in these animals. In farm breeding, where zoohygienic conditions are maintained, animal contact with the environment is prevented and the fodder is well-stored, possibilities of infection are lowered to the minimum and thus the seroprevalence is considerably lower. So it is possible to reduce the risk of $T$. gondii infection in meat-producing animals using intensive farm management with adequate measures of hygiene, confinement and preventions, such as keeping the sheds free of rodents, birds, and insects, keeping meat-producing animals indoors throughout their life-time, feeding meat-producing animals on sterilized food, controlling of access to sheds and feed stores (no pet animals).

\section{Author details}

Lenka Luptakova, Alexandra Valencakova and Pavol Balent

Department of Biology and Genetics,

University of Veterinary Medicine and Pharmacy, Kosice, The Slovak Republic

Eva Petrovova and David Mazensky

Department of Anatomy, Histology and Physiology,

University of Veterinary Medicine and Pharmacy, Kosice, The Slovak Republic 


\section{Acknowledgement}

The paper is a result of research work done within the frames of grant projects VEGA of the Ministry of Education of the Slovak Republic No. 1/0271/11

\section{References}

[1] Tenter AM, Heckeroth AR, Weiss LM (2000) T. gondii: from animals to humans. Internat. j. parasitol. 30: 1217-1258.

[2] Montoya JG (2002) Laboratory diagnosis of T. gondii infection and toxoplasmosis. J. infect. dis. 185 Suppl 1: 73-82.

[3] Olafson P, Monlux WS (1942) T. infections in animals. Cornell vet. 32: 16-190.

[4] Lang C, Gross U, Luder CG (2007) Subversion of innate and adaptive immune responses by T. gondii. Parasitol. res. 100: 191-203.

[5] Gross U, Ros T, Appoldt D, Heeseman J (1992) Improved serological diagnosis of T. gondii infection by detection of immunoglobulin A (IgA) and IgM antibodies against P30 by using the immunoblot technique. J. clin. microbiol. 30: 1436-1441.

[6] Filisetti D, Candolfi E (2004) Immune response to T. gondii. Ann. ist. super sanità 40: 7180.

[7] Reichmann G, Walker W, Villegas EN, Craig L, Cai G, Alexander J, Hunter, CA (2000) The CD40/CD40 ligand interaction is required for resistance to toxoplasmic encephalitis. Infect. immun. 68: 1312-1318.

[8] Hunter CA, Candolfi E, Subauste C, Van Cleave V, Remington J (1995) Studies on the role of interleukin-12 in acute murine toxoplasmosis. Immunol. 84: 16-20.

[9] Gazzinelli RT, Hakim FT., Hieny S, Shearer GM, Sher A (1991) Synergistic role of CD4+ and CD8+ T-lymphocytes in IFN-gamma production and protective immunity induced by attenuated T. gondii vaccine. J. immunol. 146: 286-292.

[10] Yap GS, Sher A (1999) Cell-mediated immunity to T. gondii: initiation, regulation and effector function. Immunobiology. 201: 240-247.

[11] Subauste CS (2002) CD154 and type-1 cytokine response: from hyper IgM syndrome to human immunodeficiency virus infection. J. infect. dis. 15 Suppl 1: 83-89.

[12] Abou-Bacar A, Pfaff AW, Georges S, Letscher-Bru V, Filisetti D, Villard O, Antoni E, Klein JP, Candolfi E (2004) Role of NK cells and gamma interferon in transplacental passage of $T$. gondii in a mouse model of primary infection. Infect. immun. 72: 13971401.

[13] Pinon JM, Dumon H, Chemla C, Franck J, Petersen E, Lebech M, Zufferey J, Bessieres MH, Marty P, Holliman R, Johnson J, Luyasu V, Lecolier B, Guy E, Joynson DH, Decoster A, Enders G, Pelloux H, Candolfi E (2001) Strategy of diagnosis of congenital toxoplasmosis: evaluation of methods comparing mothers and newborns and standard methods for postnatal detection of immunoglobulin G, M and A antibodies. J. clin. microbiol. 39: 2267-2271.

[14] Davidson MG (2000) Toxoplasmosis. Vet. clin. north. am. small. anim. pract. 30: 1051-1062. 
[15] Bastien P (2002) Molecular diagnosis of toxoplasmosis. Trans. r. soc. trop. med. hyg. 96: 205-215.

[16] Cassaing S, Bessières MH, Berry A, Berrebi A, Fabre R, Magnaval JF (2006) Comparison between two amplification sets for molecular diagnosis of toxoplasmosis by real-time PCR. J. clin. microbiol. 44: 720-724.

[17] Zástera M, Pokorný J, Jíra J, Valkoun A (1986) Addition of standard methods of laboratory diagnostics of toxoplasmosis. [in Czech]. Acta hyg. epidem. microbiol. Annex 3/87: 3-14.

[18] Horváth KN, Szénási Z, Danka J, Kucsera I (2005) Value of the IgG avidity in the diagnosis of recent toxoplasmosis: A comparative study of four commercially available anti-T. gondii IgG avidity assays. Acta parasitol. 50: 255-260.

[19] Cristina N, Liaud MF, Santoro F, Oury B, Ambroise-Thomas P (1991) A family of repeated DNA sequences in $T$. gondii: cloning, sequence analysis, and use in strain characterization, Exp. Parasitol. 73: 73-81.

[20] Cermáková Z, Rysková O, Plísková L (2005) Polymerase chain reaction for detection of T. gondii in human biological samples. Folia microbiol. 50: 341-344.

[21] Prelezov, P., Koinarski, V., Georgieva, D., Seroprevalence of T. gondii infection among sheep and goats in the Stara Zagora Region. Bulgarian Journal of Veterinary Medicine, 2008, 11, 113-119.

[22] Fusco G, Rinaldi L, Guarino A, Proroga YTR, Pesce A, Giuseppina DM, Cringoli G (2007) T. gondii in sheep from the Campania region (Italy). Vet. parasitol. 149; 1-4.

[23] Masala G, Porcu R, Madau L, Tanda A, Ibba B, Satta G, Tola S (2003) Survey of ovine and caprine toxoplasmosis by IFAT and PCR assays in Sardinia, Italy. Vet. parasitol. 117: 15-21.

[24] Vesco G, Buffolano W, La Chiusa S, Mancuso G, Caracappa S, Chianca A, Villari S, Currò V, Liga F, Petersen E (2007) T. gondii infections in sheep in Sicily, southern Italy. Vet. parasitol. 146: 3-8.

[25] Spisak F, Turceková L, Reiterová K, Spilovská S, Dubinsky P (2010) Prevalence estimation and genotypization of T. gondii in goats. Biologia 65: 670-674.

[26] Vostalová E, Literák I, Pavlásek I, Sedlák K (2000) Prevalence of T. gondii in finishing pigs in large-scale farm in the Czech Republic. Acta vet. Brno 69: 209-212.

[27] Spisak F, Turceková L, Reiterová K, Spilovská S, Kelemenová B, Dubinský P (2009) Epizoolotogical monitoring of toxoplasmosis in livestock in Slovakia [in Slovak]. Slovak veterinary journal 6: 384-386.

[28] Pleva J, Sokol J, Cabadaj R, Saladiová D (1997) Epizootological and epidemiological importance of toxoplasmosis [in Slovak] Slovak veterinary journal 3: 127-129.

[29] Spisak F, Turceková L, Reiterová K, Spilovská S, Dubinsky P (2010) The occurrence of T. gondii in cattle. In Proceedings of the International Conference "IX. Slovenské a české parazitologické dni [in Slovak]”, May 24.-28, Liptovský Ján, 72-73.

[30] Spilovská S, Reiterová K (2008) Seroprevalence of Neospora caninum in aborting sheep and goats in the Eastern Slovakia. Folia Veterinaria 52: 33-35.

[31] Frank RK (2001) An outbreak of toxoplasmosis in farmed mink (Mustela vison S). J. vet. invest. 13: 245-249. 
[32] Antolová D, Reiterová K, Dubinský P (2007) Seroprevalence of T. gondii in wild boars (Sus Scrofa) in the Slovak Republic. Ann. agric. environ. med. 14: 71-73.

[33] Bártová E, Sedlák K, Literák I (2006) Prevalence of T. gondii and Neospora caninum antibodies in wild boars in the Czech Republic. Vet. parasitol. 142: 150-153.

[34] Arnaudov D, Arnaudov A, Kirin D (2003) Study on the toxoplasmosis among wild animals. Exp. pathol. parasitol. 6: 51-54.

[35] Sroka J, Zwoliński J, Dutkiewicz J (2007) Seroprevalence of T. gondii in farm and wild animals from the area of Lublin province. Bull. vet. inst. Pulawy 51: 535-540.

[36] Richomme C, Aubert D, Gilot-Fromont E, Ajzenberg D, Mercier A, Ducrot C, Ferté H, Delorme D, Villena I (2009) Genetic characterization of T. gondii from wild boar (Sus scrofa) in France. Vet. parasitol. 14: 296-300.

[37] Aubert D, Ajzenberg D, Richomme C, Gilot-Fromont E, Terrier ME, De Gevigney C, Game Y, Maillard D, Gibert P, Dardé L, Villena I (2010) Molecular and biological characteristics of T. gondii isolates from wildlife in France. Vet. parasitol.171: 346-349.

[38] Martins CS, Viana JA (1988) Toxoplasmose - O que todo professional de saúde deve saber. Revista clín. vet. 15: 33-37.

[39] Lindsay DS, Dubey JP, Butler JM, Blagburn BL (1997) Mechanical transmission of T. gondii oocysty by dogs. Vet. parasitol. 73: 27-33.

[40] Valencáková A, Malceková B (2008) Detection of oocysts T. gondii in environmental samples. Proceedings of international conference „Actual questions oj animal bioclimatology [in Slovak]“, 9th-10th december, Brno, 100-102.

[41] Dubey JP, Stone D, Kwok OC, Sharma RN (2008) T. gondii and Neospora caninum antibodies in dogs from Grenada, West Indies. J. parasitol. 94: 750-751.

[42] Lopes AP, Cardoso L, Rodrigues M (2008) Serological survey of T. gondii infection in domestic cats from northeastern Portugal. Vet. parasitol. 155: 184-189.

[43] Uggla A, Mattson S, Juntti N (1990) Prevalence of antibodies to T. gondii in cats, dogs and horses in Sweden. Acta veter. scand. 31: 219-222.

[44] De Craeye S, Francart A, Chabauty J, De Vriendt V, Van Gucht S, Leroux I, Jongert E (2008) Prevalence of T. gondii infection in Belgian house cats. Vet. parasitol. 157: 128-132.

[45] Sedlák K, Bártová E (2006) The prevalence of T. gondii IgM and IgG antibodies in dogs and cats from the Czech Republic. Vet. Med-Czech 51: 555-558.

[46] Figueroa-Castillo JA, Duarte-Rosas V, Juarez-Acevedo M, Luna-Pasten H, Correa D (2006) Prevalence of $T$. gondii antibodies in rabbits (Oryctolagus cuniculus) from Mexico. J. parasitol. 92: 394-395.

[47] Sroka J, Dutkiewicz J, Toś-Luty S, Latuszyńska, J (2003) Toxoplasmosis in rabbits confirmed by strain isolation: a potential risk of infection among agricultural workers. Ann. Agric. Environ. Med. 10: 125-128.

[48] Ishikawa T, Nishino H, Ohara M, Shimosato T, Nanba K, (1990) The identification of a rabbit-transmitted cervical toxoplasmosis mimicking malignant lymphoma. Am. j. clin. pathol. 94: 107-110.

[49] Ondriska F, Catár G, Vozárov G (2003) The significance of complement fixation test in clinical diagnosis of toxoplasmosis. Bratisl. lek. listy 104: 189-96.

[50] Feldner J (1991) Toxoplasmose. Behringwerke AG. 3: 1-39 . 
[51] Catár G, Hynie-Holková, R, Zachar M (1967) The comparison of an indirect immunofluorescence and complement fixation test [in Slovak]. Bratisl. lek. listy 47: 219225.

[52] Flegr J, Havlícek J (1999) Change in the personality profile of young women with latent toxoplasmosis. Fol. parasitol. 46: 22-28.

[53] Shaapan RM, El-Nawawi FA, Tawfik MAA (2008) Sensitivity and specificity of various serological tests for the detection of $T$. gondii infection in naturally infected sheep. Vet. parasitol. 153: 359-362.

[54] Hitt JA, Filice GA (1992) Detection of T. gondii parasitemia by gene amplification, cell culture, and mouse inoculation. J. clin. microbiol. 30: 3181-3184.

[55] Van de Ven E, Melchers W, Galama J, Camps W, Meuwissen J (1991) Identification of T. gondii infections by B1 gene amplification. J. clin. microbiol. 29: 2120-2124.

[56] Kompalic-Cristo A, Frotta C, Suaárez-Mutis M, Fernandes O, Britto C (2007) Evaluation of real time PCR assay based on the repetitive B1 gene for detection of $T$. gondii in human peripheral blood. Parasitol. res.101: 619-625.

[57] Lamoril J, Molina JM, de Gouvello A, Garin YJ, Deybach JC, Modai J, Derouin F (1996) Detection by PCR of T. gondii in blood in the diagnosis of cerebral toxoplasmosis in patients with AIDS. J. clin. pathol. 49: 89-92.

[58] Truppel JH, Reifur L, Montiani-Ferreira F, Lange RR, de Castro Vilani RG, Gennari SM, Thomaz-Soccol V (2010) T. gondii in Capybara (Hydrochaeris hydrochaeris) antibodies and DNA detected by IFAT and PCR. Parasitol. res. 107: 141-146.

[59] Tenter AM (2009) T. gondii in animals used for human consumption. Mem Inst Oswaldo Cruz. 104: 364-369.

[60] Dubey JP, Kirkbride CA (1989) Economic and public health considerations of congenital toxoplasmosis in lambs. J. Am. vet. med. assoc. 195: 1715-1716.

[61] Lundén A, Uggla A (1992) Infectivity of T. gondii in mutton following curing, smoking, freezing or microwave cooking. Int. j. food microbial. 15: 357-363.

[62] Tassi P (2007) T. gondii infection in horses. A review. Parassitologia 49: 7-15.

[63] Dubey JP, Jones JL (2008) T. gondii infection in humans and animals in the United States. Int. j. parasitol. 38: 1257-1278.

[64] Robson JMB, Wood RN, Sullivan JJ, Nicolaides NJ, Lewis BR (1995) A probable foodborne outbreak of toxoplasmosis. Commun. dis. intell. 19: 517-522.

[65] Dubey JP (2000) The scientific basis for prevention of T. gondii infection: studies on tissue cyst survival, risk factors and hygiene measures. In: Ambroise-Thomas P, Petersen E, editors. Congenital toxoplasmosis: scientific background, clinical management and control. Paris: Springer-Verlag. pp. 271-5. 